\title{
On the Conditions of Possibility for Comparative and Intercultural Philosophy
}

\section{Lin Ma and Jaap van Brakel}

Affiliation: School of Philosophy, Renmin University of China, and Hoger Instituut voor Wijsbegeerte, KU Leuven (Belgium).

Address: Kardinaal Mercierplein 2, 3000 Leuven, Belgium

e-mail: lin.ma.2007@gmail.com, Jaap.vanBrakel@hiw.kuleuven.be

telephone: $+3216893968,+8615010382314$

\section{summary}

In this paper, we present a theory of intercultural philosophical dialogue and comparative philosophy, drawing on both hermeneutics and analytic philosophy. We advocate the approach of "de-essentialization" across the board. It is true that similarities and differences are always to be observed across languages and traditions, but there exist no immutable cores or essences. "De-essentialization" applies to all "levels" of concepts: everyday notions such as green and 青 qing, philosophical concepts such as emotion(s) and 情 qing, and philosophical categories such as forms of life and 道 dao. We argue that interpretation is a holistic multi-directional process constrained by the principle of mutual attunement. It is necessary to assume that "the other" is a human being, who, in most cases, is consistent and stating that which is true or right. This is the condition of possibility for intercultural philosophical dialogue and comparative philosophy. No more necessary conditions are needed. There is no need to presuppose concepts or categories that are universal for all humans and their languages (such as emotion(s) and 情 qing).

\section{keywords}

comparative philosophy, intercultural philosophy, interpretation, conditions of possibility, principle of mutual attunement, ideal language, de-essentialization 


\section{On the Conditions of Possibility for Comparative and Intercultural Philosophy}

\section{Lin Ma and Jaap van Brakel}

With recent growth in literature concerning comparative and intercultural philosophy, it has become a matter of urgency to provide an account of the relevant methodology. What seems to be prevalent among related publications is an assumption of universalism in a variety of guises. In two recent books on the methodology of comparative philosophy, there are insightful remarks in the introductory chapters, but both authors take for granted that the meaning of "similarities and differences" is self-evident, as reflected in the following statements: "Comparative philosophy should focus on two things: similarities and differences between different ways of thinking" (Burik 2009, 4); "It is as difficult to compare philosophical traditions well without reference to a critically refined comparative method as it is to develop such a method without an adequate awareness of the similarities and differences among philosophical traditions" (Smid $2009,3)$. When the notion of "similarities and differences" is simply presupposed without qualification or justification, an "ideal" tradition-independent language is also taken for granted, which is to convey the supposed similarities and differences.

Other authors more explicitly resort to a discourse of universalism. Allinson (2001). advocates a universal world philosophy that presumably transcends all localized philosophies and integrates them into one coherent world picture. Shen (2003) aims at a unified picture of contrasts or complementarities. Yu takes for granted that there can be an overarching language that allows us "to reflect upon the traditional roots of both ethics [of Confucius and Aristotle], to examine their otherwise unexamined presuppositions, and to generate alternative perspectives to determine why each side proceeds in the way it does" $(2007,4)$. These theorizations are united in presupposing that, in principle, there can be an "impartial" (Shen 2003, 357) language in which comparative or intercultural philosophy can be carried out. 
In this paper, we argue that for intercultural philosophical dialogue and comparative philosophy (henceforth: ICPD/CP) to work, there is no need to suppose that there should or could be such a language. This is the starting point of what we call the not so necessary conditions for comparison/interaction. On the other hand, we propose that the necessary conditions of possibility are not more, and not less, than what we call a principle of mutual attunement (see $§ 7){ }^{1}$

\section{Ideal language}

In the Western tradition, the dream for an ideal or universal language can be traced back to Plato and Aristotle. ${ }^{2}$ In the time of Leibniz and Descartes, formulating an ideal language was a project of great concern to philosophers. Leibniz, whose interest in the Chinese language is well known, thought that a few selected persons might be able to devise "a kind of alphabet of human thoughts in five years." In a letter to Mersenne in 1629, Descartes wrote: "I would dare to hope for a universal language very easy to learn, to speak, and to write. The greatest advantage of such a language would be the assistance it would give to men's judgment, representing matters so clearly that it would be almost impossible to go wrong."

With the development of symbolic logic, the ideal language project was given new impetus by Frege, with explicit reference to Leibniz. Frege (1892) specifies that an ideal language should be objective (eliminating individual and poetic aspects), exact (each expression has exactly one reference [Bedeutung] and one sense [Sinn]), structured or compositional (the reference and sense of each expression can be "calculated" (according to the rules of symbolic logic) from the reference and sense of its constituting parts), and each sentence is either true or false. However, as yet it has not been possible to construct an ideal language that meets Frege's criteria and in which simple natural language utterances can be expressed (such as indirect speech). ${ }^{3}$

\footnotetext{
1 The phrase "conditions of possibility" originates with Kant. A transcendental approach aims at grounding a given $S$ by finding out what makes the experience of S possible, stating its conditions of possibility. 2 See for example Aristotle, De Interpretatione, 16a3-9.

3 The intuitive notion of (a) language is presupposed. An ideal language is a particular language that meets Frege's definition. A language that is not an ideal language is "natural language". A natural language consists of a large indefinite number of language games (embedded in forms of life; see §5). Natural languages may to a lesser and increasingly greater extend be under the spell of the ideal language assumption (see §2).
} 
Perhaps the most significant feature of the ideal language assumption is that precise meanings are possible and the ideal to strive for. In our view the notion of "precise meanings" is nonsense for natural languages such as Chinese and English, including philosophical language. One might think that the word 'bachelor' has a precise meaning, namely "unmarried man," but although one might stipulate the meaning of 'bachelor' in such a way, a precise meaning of 'unmarried' and 'man' has still to be given. (And one has to accept that the Pope is a bachelor.) For "local" applications artificial "ideal" or formal languages with precisely defined meanings may make lots of sense, for example, programming languages designed to "communicate" with computers or when aiming to axiomatize a scientific theory. But to judge the relevance and success of such ideallanguage-tools, experts will communicate in a natural language such as Chinese or English. In so far as precise meanings can be introduced, this is only relative to a language that is not precise. Assume analytic philosophers and hermeneuticians both develop an ideal language to do comparative philosophy. When the analytic philosophers and the hermeneuticians would meet, they will use a natural language such as Chinese or English to discuss their respective proposed ideal languages.

The indirect appeal to the ideal language assumption reveals itself in unexpected places. It is not restricted to approaches associated with logic, artificial intelligence, or analytic philosophy. For example, Habermas' theory of communicative interaction based on his notion of an ideal speech situation, derived from Peirce's community of inquirers, allows to call into question any originally accepted conceptual scheme. However, this is all within the bounds of one "transcendental" ideal language.

One can also find traces of the ideal language assumption in those theories of communication that advocate parties to work together on a shared language as they go along. Gadamer $(1989,341)$ stipulates: "Every conversation presupposes a common language, or, it creates a common language." Charles Taylor $(1994,125)$ advocates a language of perspicuous contrast "in which the possible human variations would be so formulated that both our form of life and theirs could be perspicuously described as alternative such variations". Instead: in so far as we can speak of a fusion of horizons at all, it should be understood as pragmatic consensus in concrete situations for the purpose of continuing the exchange. 
We employ the expression "ideal language assumption" to include any account that refers to some sort of common language as the basis or objective for intercultural communication or interpretation, whether it is an explicit appeal to a Fregean ideal language (with precise discourse-independent meanings) or Gadamer's "common language." Virtually all philosophers commenting on the language-aspect of ICPD/CP assume an overarching or in-between or shared language is needed (and possible) for the communicative interaction involved in ICPD/CP. Instead we argue that, although it may seem very practical, it is not necessary to speak the same language. ${ }^{4}$

No matter what philosophy is, it cannot be independent of a particular (natural) language. The philosopher may try to overcome this limitation or deny that thinking is dependent on language, but it remains a fact that he/she uses a particular language when making these views known to others. Therefore we propose that, ideally, results of ICPD/CP should be expressed in at least two unrelated languages.

\section{Standardization and Essentialization}

The ideal language assumption comes in many guises. In this section we discuss standardization (or regimentation) of languages and essentialization of concepts. Standardization of languages mainly takes three forms:

1. For a long time, almost all languages have been accommodating themselves to modern technology, to its mode of standardization and classification inherent in technological products, even if the recipients would never employ a European language.

For over a century, linguists have been busy regimenting the remaining languages of the world.

2. Over the past half century, cognitive scientists, have been busy "fixing" the cultural universals for basic level categories (such as universal facial expressions for a small number of basic emotions) via narrowly specified experimental techniques. ${ }^{5}$

3. There are always "natural" processes of adjustment of peripheral or minority languages to the dominant language in the centre. This phenomenon has taken on a

\footnotetext{
${ }^{4}$ Note that this statement is rather trivially true in the sense that it suffices if I understand the language you speak and you understand the language I speak. I don't have to be able to speak your language and you don't have to be able to speak my language in order for communicative interaction to proceed.

5 For a critique of the reliability of such findings see van Brakel (1994) for "emotion" and van Brakel (2004) for "colour."
} 
global scale since the onset of the colonial period.

These processes of standardization pull natural languages in the direction of an ideal language. Essentialization occurs mainly in the form that particular concepts are taken to be universals with, at least in principle, one defining characteristic (the "essence"). Here are a couple of examples of essentialization and/or regimentation in the context of ICPD/CP.

1.The common practice of assuming and applying a fixed system of philosophical branches and a determinate set of basic philosophical terminology to classical Chinese texts, such that Laozi is viewed as a "metaphysician," and Zhuangzi a "skeptic."

2. Databases such as Chinese Text Project and Thesaurus Linguae Sericae employ scientifically inspired universal classifications; and map onto it the (pre-Han) meaning of Chinese characters. ${ }^{6}$

3. Providing tables in which Chinese concepts/characters are listed together with their corresponding words in Western languages too easily imply that, for instance, 情 qing has exactly the same meaning for all Chinese literati; 'emotions' has exactly the same meaning for all Western philosophers; furthermore, 情 qiing and 'emotions' share exactly the same meaning and refer to exactly the same thing. Only rather recently have some Sinologists realized that translating preHan 情 qing as emotions/passions is often wrong (Chong 2010). ${ }^{7}$

4. Assuming that such modern categories as "colour" are universals. For example, Wang (1996) often translates characters on oracle bones with (English) colour words. ${ }^{8}$ In fact, the corresponding characters indicate more than what are today recognized as different categories of colour. They include quality of the animal fur, its texture, and other features of what in English is called "appearance" (色 se).

\footnotetext{
${ }^{6}$ See their respective web pages.

${ }^{7}$ As late as Zhu Xi, “distinguishing between 是 / 非 shi/fei" is listed as one of 情 qing. Zhang Dainian $(2002,387)$ takes the view that Zhu Xi confused "the rational and the emotional spheres." This is another trace of the ideal language assumption (because Zhang considers any list of 情 qing as a list of emotions). It is now well documented that 情 qing may mean something like "a form of realizing the matter of fact." ${ }^{8}$ For example, Legge translated a passage in the 禮記 Li Ji as: "The ruler ordered the oxen to be brought before him, and inspected them; he chose them by their hair" [择其毛而卜之]. Wang (2007, p. 334) replaces "hair" by "colour." Most probably this "colour-bias" is due to the interest of anthropological linguists in colour vocabularies (which they assume to be universal).
} 


\section{De-essentialization across the board}

Instead of the ideal language assumption and essentialization, we advocate deessentialization across the board. Our notion of de-essentialization derives from Wittgenstein's notion of family resemblance. We say "across the board", because in our view, family resemblance applies to the meaning of all kinds of words, concepts, and meanings, including everyday words such as such as 'Spiel' ('game', 'play'), 'cow', and more abstract notions such as 'language', as well as philosophical terminology and categories, such as 情 qing, emotion, rationality, 道 dao, etc.

The meanings of words (concepts) are not fixed, but fluid. The mind is not to be conceived as a storehouse for meanings; the latter not as a stockpile in Plato's heaven or listed in the social contract of agreed upon conventions of a group of speakers. The meanings of utterances and inscriptions have a flexibility that resists ultimate rational reconstruction, but this does not affect the success of dialogue, good interpretation, cognitive cooperation, social engagement, poetic wanderings, and so on. Some meanings may be ascribed pragmatic identity for some length of time, but there is never an eternal essential core to meanings. Understanding utterances, inscriptions and written texts requires no more than smoothness and effectiveness of dialogue, successful negotiation and attunement. 9

Why should we de-essentialize meanings? Because we are always interpreting, ascribing meaning to many utterances or inscriptions, many beliefs, and so on, of many people (including ourselves), ${ }^{10}$ and all this at the same time (see §6). One might start to worry that de-essentialization entails an anything-goes relativism. However, its purpose is not to downgrade meanings; instead they are taken seriously. Only if meanings are de-essentialized is full-blooded communicative interaction and textual interpretation possible.

Natural language is full of ambiguities, malapropisms and hybridities, but in principle this does not obstruct communication or interpretation. What is called language by lin-

\footnotetext{
9 Following Quine $(1990,47,59)$.

${ }_{10}$ As argued by Ryle, Strawson and Davidson, among others, we don't see any better when we inspect our own minds than when we inspect the minds of others.
} 
guists and philosophers does not exist. ${ }^{11}$ What exist, at best, are passing idiolects or dynamic "momentary" theories of interpretation (van Brakel 1996). In order for communicative interaction to proceed, there is no need to share a language, not even a newly created common or "in-between" language. If communicative interaction is taking place, participants in the endeavour will exploit whatever common ground they can find. ${ }^{12}$ But different participants may see and experience different apparent common grounds, and in particular will give very different descriptions of the shared world they participate in. Note that this statement is made from an observer's third-person perspective and it is not as extreme as it may seem. Participants may have quite different conceptual classification schemes which are sufficiently similar not to obstruct communication in any principled way. In addition in ongoing interaction they may learn some of the other's idiosyncracies. ${ }^{13}$

\section{Traditions}

Generally speaking, when one uses the word "tradition," one has in mind a web of beliefs, common behaviour, customs, and material products that are passed down within a society or within one part of a society. The German word for tradition, Überlieferung, literally meaning "what is carried down," conveys very well the aspect of historicality of a tradition. When we come to the notion of a philosophical tradition, we can try to make it more clear by differentiating between three interconnected "features": [i] language(s) being used, [ii] philosophical content of relevant conceptual schemes or theories, and [iii] surrounding culture or forms of life. The notions of conceptual schemes and forms of life will be explicated in the next section. ${ }^{14}$

\footnotetext{
11 Paraphrasing Davidson (1986)

${ }^{12}$ In addition, differences between idiolects keep language dynamic; which is why Kuhn could say that incommensurability is the motor of scientific progress.

13 Also note that statements with one and the same truth condition may have widely differing philosophically relevant interpretations. For example, we cannot be sure whether Gongsun Long's 白馬非馬 bai ma fei ma was meant to be true or false (cf. note 23), but for each of the two options there are many alternative philosophically different understandings (in terms of universals, mass nouns, etc.)

${ }^{14}$ We are well aware of Davidson's critique of the notion of conceptual scheme, except that we use 'conceptual scheme' in a different way (to be explained in §5). Our use of 'conceptual scheme' has some similarity to Graham's use. In a rather neglected paper Graham (1992) provides a very clear exposition of the way in which his notion is different from that of Davidson.
} 
A tradition is heterogeneous; it should not be essentialized (it is the same case with the notion of culture). We can say that European and Japanese philosophies are heterogeneous traditions, as are phenomenology and Daoism. The thoughts of Heidegger and Laozi, including their commentators, can also be said to be heterogeneous traditions. Hence, philosophical traditions can be "grand" (for example, "the Eastern tradition") or "small" (for example, the ideas embodied in Being and Time or the Daodejing). A particular tradition or a philosopher will usually, to a greater or lesser extent, adjust the language of the "local" culture or life-world for its own purposes. For example, Heidegger has to a large extent coined new words on the basis of German language in order to effectively express his thinking.

The notion of "intercultural philosophical dialogue" can also be taken in a narrower or a wider sense. In accordance with current usage, we would not call a discussion between Heidegger and Carnap, or between Laozi and Kongzi, an intercultural philosophical dialogue; whereas we would certainly consider a discussion of Heidegger with the Japanese (Buddhist) philosopher Hisamatsu an intercultural philosophical dialogue (although the conversation was carried out in the German language!).

If we apply the principle of de-essentialization across the board, we can see that it is not only for intercultural philosophical dialogue that languages and presuppositions differ. In a discussion between Heidegger and Carnap, or between Laozi and Kongzi, there also exist undeniable divergence. There are differences of different degrees, but there is no fundamental difference between "inter-" and "intra-"cultural philosophical dialogue. In a similar sense, it can be said that all philosophy is comparative philosophy. The suggestion that two traditions might be "incommensurable" or inaccessible to one another is a remnant of the ideal language assumption. There is always some understanding and some misunderstanding; there is no such thing as complete understanding.

If philosophers or traditions recognise each other as (to some extent, in certain respects) philosophical traditions, then there is room for intercultural philosophical dialogue. However, it is not required that all involved share the same notion of philosophy. Also the notion of philosophy is a family-resemblance notion. It is open for discussion 
whether the words 'philosophy' and ‘哲學 zhexue' have the same sense. If they don't, as is sometimes argued, this does not undermine the possibility of ICPD/CP. ${ }^{15}$

\section{Forms of life and conceptual schemes}

In addition to the language it uses, a tradition has to be understood in connection with "forms of life" and "conceptual schemes". ${ }^{16}$ Roughly speaking, 'forms of life' refers to the cultural milieu in which a particular philosopher lives; 'conceptual schemes' refers to the philosophical reflections in a tradition, or more specifically, to the theories or systems of philosophy in a tradition.

Forms of life include the whole of the moral, social, historical, communicative, religious, mythical, private discernments and orders. They give rise to the language games of a tradition and constitute the grounds of the conceptual schemes in a tradition. Strictly speaking, it does not make sense to ask for an explanation of "forms of life." This is because they are the very ground on which any possible justification or interpretation would rest. They constitute the background against which something can be said to be right or wrong. Any inquiry, reflection, or interpretation is co-generative with the tacit, pre-formational contingencies of the forms of life.

By writing 'form(s) of life' with the pluralizing 's' in brackets, we mean to convey the idea that the "pre-notional" notion "form(s) of life" should be understood to be the empirical as well as transcendental grounding of human action and reflection, to be moral as well as cognitive basis of human community, and to have a universal as well as a local range of human behaviour. ${ }^{17}$ There is both one and many human forms of life. It is wrong to take forms of life only in the plural sense, because all forms of life have in common their humanness. There is one human form of life as distinct from the form of life of lions. It is also wrong to take forms of life only in the singular sense, because similarities and differences in human life crop up and disappear, without a common core. It

\footnotetext{
15 An example of the dynamics of the extension of 'philosophy' is the entry of discourses such as Yoruba epistemology and Akan causality, which were not considered to be philosophy a few decades ago, into the Routledge Encyclopaedia in Philosophy. Not all philosophers would agree with this editorial decision.

16 The original occurrences of Lebensform(en) are in Wittgenstein $(2001$ : $\S \S 19,23,241$; pp. 174, 226) and a few other places in his Nachlass, which remained unpublished during his lifetime.

17 The "pre-notional" notion of form(s) of life is the basis for the requirement of de-essentialization and the suggestion "no need to speak the same language."
} 
is both an empirical and a transcendental precondition for a human person that one is embedded in the certainties of particular forms of life. In the meantime, one is capable of recognizing and dealing with the indefinite varieties of the human forms of life. There is no abysmal boundary between forms of life or traditions. Any ordering of traditions is subject to the historical development of interacting forms of life, language games, and conceptual schemes.

It can never be sufficiently stressed that forms of life should never be understood as something static and absolutely binding. Although Wittgenstein once suggested that forms of life are the bedrock of human action, one should not derive from this remark the idea that forms of life are unchangeable and human beings are passively at their mercy. Certainly, functioning like bedrock, forms of life in normal situations provide secure orientations; nevertheless, there are days in which bedrock (no matter it is rock bottom or river-bed) gives way. Moreover, over a long time, bedrock will completely change itself.

As already mentioned we use the phrase "conceptual schemes" to stand for the ideas, opinions, and theories of a particular philosopher or a tradition. A concept or idea is that which is understood with a term (that is, its meaning). A conceptual scheme is a system of concepts that organises thought and experience. In case a philosopher is opposed to the use of concepts that would inappropriately regiment thinking, relevant interpreters and commentators would still employ conceptual schemes to decipher his/her work.

Prima facie conceptual schemes are inextricably connected with language. One can even say that a conceptual scheme is a language that purports to discuss a specific subject matter. Philosophers easily tend to conceive a conceptual scheme in analogy with an ideal language. For example, both Quine and the later Mohists attempt to provide strict definitions for "all" the terms that are used in a conceptual scheme. ${ }^{18}$ However, no matter how terms are to be defined, one cannot but use a natural language to do that. Therefore, the choice and justification of a particular conceptual scheme is ultimately grounded in language games (which can not be formalised) embedded in (deessentialized) forms of life. But a conceptual scheme doesn't have to aspire to become a

18 The "later Mohists" refers to an influential philosophical, social, and religious movement during China's Warring States period (479-221 BCE). 
highly regimented language. Listing a number of central characters used in the Daodejing together with some explanation and a few remarks on their interrelations and relations to the scholarly Chinese of its time is also already presenting a (sketch of a) conceptual scheme.

It is commonly seen that scholars associate with a philosopher or a tradition no more than one conceptual scheme. In the light of our plea for de-essentialization, it is crucial to realize that a large number of conceptual schemes are simultaneously at play in the thinking of a philosopher or in a tradition. Furthermore, the ways in which a conceptual scheme receives determination are indefinite. Any one scheme among all other ones, no matter how well formalized or empirically adequate, is nothing more than a sophisticated abstraction from numerous language games of a tradition - this manifold can never be completely described. It is true that each scheme fits "a world" (or a subject matter); nevertheless, each utterance about such a world can only be a co-production of a number of schemes.

A proper understanding of conceptual schemes and forms of life as outlined above has important consequences for understanding the notion of similarity. When speaking about similarities and differences one has to be aware that such observations are always relative to numerous conceptual schemes. There cannot be one universal ideal discourse for the discernment of similarities and differences. This does not mean that any story goes. There can be good reasons why a particular conceptual scheme works better or fits better than other schemes. Over a long period of time, the better schemes would survive while some others would be discarded. This is somewhat like a selection process. What is similar and different has to be claimed and re-claimed in all human interactions and interpretative endeavours again and again. The acts of claiming and reclaiming should not be understood in individualistic terms. They are part of a complicated process of triangulation between different interpreters, the relevant languages and traditions, and the world(s) described by the respective conceptual schemes. Further, identification of similarities and differences is dependent on the forms of life that are compared as well as the conceptual schemes available to those who are doing the identification or making the comparisons. 


\section{XYZ-model of interpretation and comparison}

In this section, we propose a model of intercultural communicative interaction that is applicable to ICPD/CP, seen as a complex of multiple intercultural dialogues. The model contains ingredients from both hermeneutics and analytic philosophy. Although there are differences between face-to-face intercultural encounter between two human beings and interpretation of an ancient text from another tradition, the basic features of intercultural communicative interaction are the same.

Consider the words of a philosopher or other human being, being interpreted by another human being. To make things concrete think of the conversation that actually took place in 1958 at Heidegger's home between the German philosopher Heidegger and the Japanese Buddhist philosopher Hisamatsu. ${ }^{19}$ In describing the model we will regularly speak of the interpreter $\mathrm{Y}$ interpreting $\mathrm{X}$, but of course $\mathrm{X}$ is also interpreting $\mathrm{Y}$. There is mutual attunement.

$\mathrm{Y}$ uses observations of X together with Y's background knowledge and attitudes to provide interpretations of X('s writings).

The observations include:

- X's (un-interpreted) utterances and inscriptions;

- X's other actions;

- circumstances in which X is situated.

These observations are not "neutral", but depend on the interpreter's "background," which consists of:

- general beliefs, expectations, values, etc.;

- knowledge of what has been said about X's utterances and X's historical embedment in specific circumstances (tradition, forms of life);

- whatever else that might influence or bear on Y's observations and interpretations.

In cases such as "first encounters," X's behaviour and circumstances play a more important role than the interpreter's background knowledge (except for a general notion of what might be expected of a human being); while in cases of comparative philosophy,

\footnotetext{
${ }^{19}$ For an account of this discussion see Ma $(2008,73)$.
} 
typically the interpreter's background knowledge of what others have already said about X will be dominant.

Observations and background knowledge together allow the interpreter to generate hypotheses concerning:

- Meanings of X's utterances and inscriptions, including complete theories, webs of beliefs, or other conceptual schemes (i.e. "translations" in terms of Y's language).

- Beliefs, motivations, goals, and other attitudes of X.

- Presupposed background of the meanings, beliefs, etc just mentioned (i.e. X's background).

The general features of the model hold no matter how close or how far the "distance" is between $\mathrm{X}$ and Y. The particular subdivision of the observations, background, and interpretation is not rigid. Finer discriminations and more "parameters" can be added.

The model is (just) complicated enough to point out most of what is important for interpretation. First of all there is not one thing that is interpreted but many things at the same time, which form a holistic whole. Beliefs of X and meanings of X's words (and other things) are always interpreted at the same time. This might be called a hermeneutic circle. There is holism across the board. For example, meanings of many words are interpreted at the same time, not one by one. Interpretation of work and corpus, passage and work, etcetera are all interdependent. There is also a circle going from Y's interpretations of X, to Y's behaviour (including utterances), to X's interpretations of the latter, to X's behaviour, to Y's interpretation of the latter. Further, results of interpretation can be added to or replace part of the background (of $\mathrm{Y}$ and $\mathrm{X}$ respectively), but the original background cannot be eliminated or transcended completely (which might be called hermeneutic relativity).

Using the hermeneuticians' advice to model the interpretation of a text in terms of having a dialogue with the text, the same model can be applied to interpreting text X. For example Heidegger interpreting chapter 28 of the Daodejing. ${ }^{20}$ Usually a large number of Y would be involved in the project of interpreting X. Some may focus more on reconstruction of the text; others on its interpretation. Some would claim to have access to

${ }^{20}$ For discussion of this example see Ma (2006). 
the "original meaning" of $\mathrm{X}$ and claim to speak as a representative of (the author of) X. Other Y may aim for an interpretation that is relevant to and directed at a particular audience. Further, X's “words" normally have already been been around for a long time, translated into foreign languages and received various interpretations either in the same or in another tradition. Commentators who have deceased have to be represented by some contemporary philosophers, either in the original language or in later translations or renderings. Furthermore X contributes to contemporary philosophical discussions both directly through the "original" text and indirectly via later interpretations, commentaries, and translations. Reconstruction of the original text, earlier and later commentaries, translations, and interpretations, and so on are holistically related in the ongoing process of interpretation. Thus, interpreting X can be understood as a dialogue among all philosophers, translators, commentators, etc. involved.

The model to be proposed for comparative philosophy will be slightly more complicated, introducing $\mathrm{Z}$ who is comparing $\mathrm{X}$ and $\mathrm{Y}$; but it is still based on the basic face-toface dialogical model. Consider the comparison of (texts, philosophers, traditions) $\mathrm{X}$ and Y. For each of $\mathrm{X}$ and $\mathrm{Y}$ what has been said for the model of interpreting a text applies: $\mathrm{a}$ group of philosophers is involved in interpreting $X$ (and in dialogue among one another concerning their interpretations) and another group is involved in interpreting Y. We will say that these groups (which may or may not partly overlap as to the composing individuals) represent $\mathrm{X}$ and $\mathrm{Y}$. We propose that a comparison of $\mathrm{X}$ and $\mathrm{Y}$ is to be modelled in the form of an imaginary dialogue between $\mathrm{X}$ and $\mathrm{Y}$ being constructed by $\mathrm{Z}$. For example, Joan Stambaugh (1991) has published an imaginary dialogue between Heidegger and a Buddhist. In presenting this dialogue Stambaugh is indirectly in dialogue with the interpreters of Heidegger, with the interpreters of Buddhism, and with scholars who compare Heidegger and Buddhism. Of course Stambaugh herself may and probably will also belong to the group of interpreters of Heidegger and the group of interpreters of Buddhism.

So, comparative philosophy is modelled as setting up imaginary dialogues between various $\mathrm{X}$ and $\mathrm{Y}$, the latter two being represented by two groups of interpreters respectively, each group being in dialogue among one another, whereas those who are setting up such an imaginary dialogue are thought to be in dialogue with the groups represent- 
ing $\mathrm{X}$ and $\mathrm{Y}$, as well as in dialogue among one another. ${ }^{21}$

\section{Principle of mutual attunement}

Meaning, belief, attitude, and all other facets in communicative interaction are interdependent; one cannot interpret any one facet from the triad observation, background and interpretation separately. Whenever one comes up with an interpretation of one facet, one would have already assumed an implicit interpretation of all other facets. Therefore, there is under-determination (rather similar to the underdetermination of a scientific theory by the evidence). In order for interpretation and understanding to be possible, there has to be a minimal constraint. We suggest that this minimal constraint is none other than the principle of mutual attunement. The starting point of this principle is: one interlocutor approaches the other interlocutor as a human being. Further, according to the principle of mutual attunement, the interpreter must presuppose that $\mathrm{X}$ usually is sincere, speaks the truth, speaks consistently, and often aims for what is right, such conceptions as truth, consistency and what is right being understood according to the interpreter's criteria and formulated in his or her language. This holds true the other way around as well, that is, for $\mathrm{X}$ being the interpreter (using his or her criteria and language).

The principle of mutual attunement bears similarity to Davidson's principle of charity. According to Davidson (1984), for interpretation to be possible, the interpreter needs to presuppose that the speaker is "consistent, a believer of truths, and a lover of the good" (1980, 222). The principle of mutual attunement agrees with Davidson's principle on this point; but it differs from it in two aspects. First, for Davidson, logic, and the notion of belief (i.e. "holding true") and some other matters are assumed to be universal across all humans and their languages and so do not need to be interpreted. In our view nothing should be excluded from interpretation, not even logic. ${ }^{22}$ No universals need to be presupposed. Second, Davidson's principle is only concerned with one-way oral

21 The model can be formalized as follows: $Z_{i}\left[X\left(Z_{j}\right) Y\left(Z_{k}\right)\right]$, i.e. a number of philosophers $Z_{i}$ are in dialogue concerning the comparison of $X$ (as represented by $Z_{j}$ ) and $Y$ (as represented by $Z_{k}$ ) by setting up an imaginary dialogue between $X$ and $Y . Z_{i}$ are in dialogue with $Z_{j}, Z_{k}$, and among one another. A single philosopher may come under more than one of the parameters $\mathrm{X}, \mathrm{Y}, \mathrm{Z}_{\mathrm{i}}, \mathrm{Z}_{\mathrm{j}}$, and $\mathrm{Z}_{\mathrm{k}}$,

22 Recent language games of alternative logics, the discussion about justification of deductive logic, and disagreements about the interpretation of various ethno-logics show there is no safe ground for, say, first order predicate logic, to be a universal constraint on all utterances in a language. 
interpretation or a "third person perspective" and the role of interpretor and speaker are more or less fixated. With the principle of mutual attunement, interpretation is a dynamic process in which two interlocutors interact with one another as described in the XYZ-model. In a face-to-face situation, interaction goes in both directions. Hence, it should be a process of mutual attunement (but which includes contestation). If "the other" is deceased, the dynamism is operative in the dialogue among contemporary interpreters and commentators, as elucidated in $\S 6$.

Every particular interpretation depends on innumerable other interpretations, each of which can be wrong, but many have to be right lest any sense of interpretation is lost. Only relative to the other on the whole being right can one ascribe to her or him logical, epistemic, or deontic errors. One can have disagreements with the other only against a background of agreements; one can misunderstand the other only against a background of understanding.

As in Quine's (1990) holistic web of belief any particular interpretation can be "corrected" by changing some other facet of the cluster of interpretations. For example, if $Y$ notices an inconsistency in the beliefs of $X$, the conclusion of inconsistency (in terms of Y's criteria of course) may be well supported, but it may be possible to remove the inconsistency by assuming the meaning or force of some of X's utterances to be different. 23

The principle of mutual attunement is applied in terms of the criteria of the interpreter, but as the interpretation of X advances, $Y$ may also start to interpret by X's lights (as understood by the Y's lights of course). ${ }^{24}$ All this applies as much to interpreting the familiar (Other) as the alien (Other). There is no principled difference between dialogue and interpretation within and across traditions.

At an even later stage of interpretation, there may be reasons to change the wording of the principle of mutual attunement. It is not assumed that the words used in the formulation of the principle name universals.

Of course, if one believes having reasons to presuppose some kind of universals (cf. $\S 2$ ), the open-endedness and undeterminedness of the process of interpretation can be

${ }^{23} \mathrm{~A}$ concrete example of balancing beliefs and meanings differently might be the discussion on Gongsun Long's "white-horse not horse" (Cheng 2007, Hansen 2007).

${ }^{24}$ This might be seen as moving from the principle of charity to that of humanity in the course of the interpretative process, resolving Hansen's critique of Davidson's principle of charity. 
limited considerably. We argue that the principle of mutual attunement is the only necessary assumption needed for interpretation, apart from the more basic assumption that the other is a human being, towards whom one is having an attitude that is, in Wittgenstein's words, "an attitude towards a soul" (2001, II, iv). Other assumptions may make the task easier, but they are not necessary and therefore better avoided, because they too easily lead to ethnocentrism, hegemony or a form of non-communication. ${ }^{25}$ There is no need for horizon fusion, no presupposition of universal understandability, no need for a shared language or language in-between, no need for cognitive or linguistic universals (at least not the ones that are often mentioned). Family resemblance across the board and the principle of mutual attunement always already make interpretation, understanding, comparison possible, at least to some degree.

\section{Planetarization - globalisation}

In the contemporary world every philosopher has been influenced to a greater or lesser extent by European history of ideas. Perhaps the cooperation of Li Zhizao (李之 藻,1565-1630) and Francisco Furtado concerning the translation of a Latin edition and commentary of Aristotle's Categoriae into Chinese in the seventeenth century was still a relatively pure case of intercultural encounter, but in the world of today a philosopher in Africa or China (or Europe or America for that matter) is not free to think completely free of European influences. As Heidegger $(1957,145-46)$ remarked after raising the question of the accessibility of "the ancient world of the Indies, China and Japan" to Western thought, ${ }^{26}$

This question becomes even more urgent, because European thinking is threatening to become planetary, in that contemporary Indians, Chinese and Japanese can usually bring to us what is experienced by them only through our European way of thinking. Thus from there and from here everything is stirred around in an enormous hodgepodge, in which one cannot distinguish any more whether the ancient Indians were English empiricists and Laotse a Kantian.

25 As to the latter compare the "dialogue" between Gadamer and Derrida (Michelfelder en Palmer 1989, $55,76,129,186,192,206,251)$. Concerning aspects of hegemony see for example Tully (1995).

26 This is one of the many citations showing Heidegger's occasional ponderings concerning the need and/or possibility of an East-West dialogue at a "deep level." See for discussion Ma (2008). 
The process of globalisation, which Heidegger refers to with the word 'planetarization' causes a form of hermeneutic relativity which is becoming more and more difficult to overcome. All similarities and differences have to fit into one dominant (Englishlanguage dominated) discourse, which in addition is being more and more standardised (or regimented) and essentialised as a result of the developments of science and technology (cf. §2). Even a Chinese philosopher working in China, specialising in Chinese philosophy, and publishing only in Chinese cannot avoid the globalised academic world. ${ }^{27}$

Here is an example of the impossibility of discussing a non-Western concept or category independent of western discourses. Consider the saying (expressed in Xhosa, one of the eleven official languages of South Africa): Umu-ntu ng-umu-ntu ng-aba-ntu (Louw 2001). Many alternative translations exist of this phrase, a popular one being "a human being is a human being through other human beings," claimed by some to express a notion similar to harmony, but allegedly fundamentally different from any Western and Eastern notion of self. How can we have access to traditional meanings of this utterance if those writing about it, have been educated in a French or English educational system? In philosophical publications this saying has been discussed at length, using the key term ubuntu. In the first paragraph of their article authors will usually cite the saying cited above (or a variant of it in an other Bantu language), writing as if the word ubuntu occurs in the saying. Without exception scholarly articles on ubuntu (or white papers of the South African government) are in the business of writing about an essentialized notion ubuntu and its relevance for the contemporary globalised world. This may be a laudable engagement, but the interpretation of the utterance quoted is not addressed. ${ }^{28}$ The word ubuntu, drawing on its association with communities of human beings already occurs on more than 40,000,000 web pages (rising steadily). Almost all of these pages have nothing whatsoever to do with (African) philosophy.

In the case of ubuntu an insurmountable constraint is that there are no ancient written texts mentioning ubuntu. Is it still possible to interpret classical Chinese texts with-

\footnotetext{
27 If only because his or her government has just decided that the one crucial criterion for promotion to full professor is having publications in journals listed in the American Arts \& Humanities Citation Index.

${ }^{28}$ Ramose (1999) has argued that the -umu/-ubu prefixes undermine the standard western distinction between ontological and epistemological issues.
} 
out using conceptual schemes that originate in European languages? One might say: "Of course this is possible: by writing in Chinese." But modern Chinese contains more than one thousand neologisms, including many loan words, which are introduced to render European philosophical notions such as Being, philosophy, logic, ontology (Liu 1995). Even notions such as concept and category come into Chinese as neologism (Zhang 2002, xxiii).

\section{Concluding remarks}

When it comes to intercultural dialogue and comparative philosophy, universalism and relativism are the two commonly assumed positions. However, both universalism and relativism suffer from the ideal language assumption. The universalist assumes that there eventually has to be one ideal language in which intercultural philosophical dialogue can be carried out and the results of comparative philosophy can be best expressed. The relativist assumes that, for each philosopher or philosophical tradition, there is one ideal language. Hence, different traditions are incommensurable.

We have argued that the assumption of ideal language is derived from a wrongheaded understanding of language. We apply Wittgenstein's notion of family resemblance to words or concepts across the board. All concepts have to be de-essentialized (that is, there are similarities and differences, but no cores or essences). Family resemblance of concepts applies both within and across traditions and allows for alternative classifications of "resemblance families."

We have presented a model of interpretation for intercultural philosophical dialogue, comparative philosophy (and intercultural communicative interaction in general), which has no need for any concepts or categories to be universally shared among all human traditions. The only, nevertheless indispensable, condition of possibility for interaction between (philosophical) traditions is the principle of mutual attunement. The starting point of this principle is that the interpreter recognizes "the other" (whose utterances or inscriptions are being interpreted) as a human being. In addition it must be assumed that "the other" is usually sincere, consistent and saying or writing that which is true or right. Accessibility and adequacy of interpretation of philosophical 
thought is a matter of degree, subject to the principle of mutual attunement. Interpretation (translation, understanding) is always possible to some extent, whereas the idea of "complete understanding" is nonsense.

In fact, the hurdles involved in interpreting an ancient text derive mainly from globalization. There are now no languages or philosophical discussions that remain untainted by neologisms and conceptualisations derived from modern European languages and the history of Western philosophy.

\section{References}

Allinson, Robert E. 2001. The Myth of Comparative Philosophy or the Comparative Philosophy Malgré Lui. In Two Roads to Wisdom? - Chinese and Analytical Philosophical Traditions, edited by B. Mou, Chicago: Open Court.

Burik, Steven. 2009. The End of Comparative Philosophy and the Task of Comparative Philosophy: Heidegger, Derrida and Daoism. Albany: State University of New York Press.

Cheng, Chung-ying. Reinterpreting Gongsun Longzi and Critical Comments on Other Interpretations. Journal of Chinese Philosophy 34 (2007): 537-60.

Chong, Kim Chong. 2010. Zhuangzi and Hui Shi on Qing 情. Tsing Hua Journal of Chinese Studies New Series 40 (1):21-45.

Davidson, Donald 1980. Essays on Actions \& Events. Oxford: Clarendon Press.

-_- 1984. Inquiries into Truth and Interpretation. Oxford: Clarendon Press

———. 1986. A Nice Derangement of Epitaphs. In Truth and Interpretation: Perspectives on the philosophy of Donald Davidson. Oxford: Blackwell.

Frege, Gottlob (1892) Über Sinn und Bedeutung, Zeitschrift für Philosophie und philosophische Kritik, 100: 25-50;.

Gadamer, H.-G. (1989) Truth and Method, New York: Continuum; 2nd revised edition, 1st edition 1975.

Graham, A.C. 1992. Conceptual schemes and linguistic relativism in relation to Chinese. In Unreason Within Reason: Essays of the Outskirts of Rationality, edited by A. C. Graham. La Salle IL: Open Court.

Hansen, Chad. Prolegomena to Future Solutions to 'White-Horse Not Horse'. Journal of 
Chinese Philosophy 34 (2007): 473-91.

Heidegger, M. (1957) Bremer und Freiburger Vorträge. Vol. 79, Gesamtausgabe. Frankfurt a/M: Klostermann.

Liu, Lydia H. (1995) Translingual Practice: Literature, National Culture, and Translated Modernity-China, 1900-1937, Stanford: Stanford University Press.

Louw, Dirk J. 2001. Ubuntu and the Challenges of Multiculturalism in post-apartheid South Africa. Quest 15:1-16.

Ma, Lin. 2006. Deciphering Heidegger's Connection with the Daodejing. Asian Philosophy 16:149-171.

-_- 2008. Heidegger on East-West Dialogue: Anticipating the Event. New York: Routledge. Michelfelder, D.P., and R.E. Palmers, eds. 1989. Dialogue \& Deconstruction: The GadamerDerrida Encounter. Albany: SUNY.

Quine, W.V. (1990) The Pursuit of Truth, Cambridge MA: Harvard University Press. Ramose, Mogobe. B. 1999. African Philosophy Through Ubuntu. Harare: Mond Books. Shen, Vincent. 2003. Some Thoughts on Intercultural Philosophy and Chinese Philosophy. Journal of Chinese Philosophy 30:357-372.

Smid, Robert W. 2009. Methodologies of Comparative Philosophy: The pragmatist and process traditions. Albany: State University of New York Press.

Stambaugh, Joan. 1991. Imaginary dialogue between Heidegger and a Buddhist with apologies for possible implausibilities of personalities. Eastern Buddhist 24 (1):123-134.

Taylor, Charles et al. (1994) Multiculturalism, Princeton: Princeton University Press. Tully, James (1995) Strange Multiplicity: Constitutionalism in an Age of Diversity, Cambridge: Cambridge University Press.

van Brakel, Jaap. 1994. Emotions: A cross-cultural perspective on forms of life. In Social Perspectives on Emotion, edited by W. M. Wentworth and J. Ryan. Greenwich USA: JAI Press.

- - - 2004. The empirical stance and the colour war. Divinatio: Studia Culturologica (Sofia: MSHS) 20:7-26.

- - 2006. De-essentialising across the board: No neede to speak the same language. Rechtsfilosofie \& Rechtstheorie 35:263-284.

Wang, Tao. 1996. Colour Terms in Shang oracle bone Inscriptions. Bulletin of the School of Oriental and African Studies 59 (1):63-101. 
- - 2007. Shang ritual animals: colour and meaning (part 1) Bulletin of the School of Oriental and African Studies 70:305-372.

Wittgenstein, Ludwig (2001 [1953]) Philosophical Investigations, Oxford: Basil Blackwell.

Yu, Jiyuan. 2007. The Ethics of Confucius and Aristotle: Mirrors of Virtue. New York: Routledge. Zhang, Dainian. 2002. Key Concepts in Chinese Philosophy. New Haven/London: Yale University Press. 